\title{
Self-Medication Practices among Diabetic Patients in Kuwait
}

\author{
Abdelmoneim Awad Shahd Al-Rabiy Eman Abahussain \\ Department of Pharmacy Practice, Faculty of Pharmacy, Health Sciences Centre, Kuwait University, Kuwait
}

\section{Key Words}

Self-medication - Over-the-counter drugs $\cdot$ Herbs $\cdot$ Kuwait • Diabetic patients

\begin{abstract}
Objectives: The aim of this study was to estimate the prevalence of self-medication with proprietary medicines and/or herbs among diabetic patients and evaluate factors associated with self-medication among diabetic patients. Subjects and Methods: A total of 104 diabetic patients were selected randomly from eight diabetic clinics from three governorates. Data were collected via face-to-face structured interview of the respondents in the clinics using a developed and piloted questionnaire. Results: The response rate was $96.2 \%$. Seventy-four percent of the study participants reported that they seek medical consultation when they get an illness, 92\% indicated that they know that the use of medicines and/or herbs to treat an illness without a medical consultation can be harmful. Only $13 \%$ of the respondents reported that they had used medicine or herbs without medical consultation to treat an illness within the previous 2 months of the study period. Nine percent of the study population reported that they used herbs to treat diabetes, and $2 \%$ used them for other illness. Only two (2\%) indicated that they used medicines, which were analgesics, diet pills and vitamins. There was no significant association between self-medication with medicines or herbs and the sociodemographic characteristics of the respondents $(p>$ 0.05). Conclusion: The prevalence of self-medication with
\end{abstract}

(C) 2008 S. Karger AG, Basel

1011-7571/08/0174-0315\$24.50/0

Fax +4161306 1234

E-Mail karger@karger.ch

www.karger.com
Accessible online at: www.karger.com/mpp medicines, including herbs, among diabetic patients in Kuwait is low. Enforcement of a strict prescription policy and coverage of medical consultation and treatment by health insurance may have contributed to low self-medication practices among diabetic patients.

Copyright $\odot 2008$ S. Karger AG, Basel

\section{Introduction}

Self-medication can be defined as the use of drugs to treat self-diagnosed disorders or symptoms or the intermittent or continued use of prescribed drugs for chronic or recurrent disease or symptoms [1]. It is usually selected by consumers for symptoms that they regard as troublesome enough to require drug therapy but not to justify the consultation of a medical practitioner. In developing countries, most illnesses are treated by self-medication $[2,3]$. A major shortfall of self-medication is the lack of clinical evaluation of the condition by a trained medical professional, which could result in missed diagnoses and delays in appropriate treatments [4]. Therefore, self-medication may result in drug-induced disease and waste of public health expenditure [5]. Several published articles have provided the prevalence of self-medication with proprietary medicines and/or herbs and factors associated with it [6-13].

Diabetic patients may get minor ailments for which they prefer treatment with an over-the-counter (OTC) drug and/or herb. Diabetic patients should seek physician

Dr. Abdelmoneim I. Awad, Assistant Prof.

Department of Pharmacy Practice, Faculty of Pharmacy, Health Sciences Centre Kuwait University, PO Box 24923

13110 Safat (Kuwait)

Tel. +965498 6914, Fax +965 498 6840, E-Mail amoneim@hsc.edu.kw 
or pharmacist advice about these remedies beforehand because their use may result in adverse effects [14]. The following are examples: (a) The chronic use of non-steroidal anti-inflammatory drugs such as ibuprofen (OTC drug) will worsen the renal function of diabetic patients. (b) Oral nasal decongestants may increase blood glucose by preventing insulin secretion, decrease glucose uptake by periphery, and increase glycogenolysis. Moreover, they may increase blood pressure and worsen the retinopathy complications and heart disease of the diabetic patients. (c) Cough syrups may contain alcohol or sucrose that adversely affect the control of diabetes [14]. Ginkgo biloba is a herbal remedy, which, when used by diabetic patients, affects their insulin level; therefore, an adjustment of drug therapy is needed for those who intend to use the herb [15].

Inappropriate self-medication among diabetic patients may lead to poor control of blood glucose levels. Diabetes is a serious progressive disorder and uncontrolled blood glucose level may lead to complications. There is a lack of information about the prevalence of self-medication among diabetic patients. This study was designed to estimate the prevalence of self-medication with proprietary medicines and/or herbs among diabetic patients and to evaluate factors associated with self-medication among diabetic patients.

\section{Subjects and Methods}

A cross-sectional survey of 100 diabetic patients (60 males and 40 females) selected randomly from eight diabetic clinics in three governorates, Hawalli, Al-Farwaniyah, and Capital of Kuwait, was conducted using both open and closed-ended questions. The questionnaire, which contained four sections, was translated into Arabic and pilot tested in 10 diabetic patients to evaluate readability and comprehension. The first section included questions on gender, age, nationality, educational level, employment, residence, monthly income, and membership of diabetes association of Kuwait. The second section was used to evaluate the healthseeking behaviour of the diabetic patients regarding the medical consultation when they contract an illness, and the use of medicines and/or herbs without medical consultation. The third and fourth sections were used to measure the prevalence of self-medication with herbs and proprietary medicines, respectively, to treat diabetes.

Data were collected via face-to-face structured interview of the respondents in the diabetic clinics using the questionnaire from February to April 2005. The interviews conducted by one person (S.A.) lasted approximately 15-20 $\mathrm{min}$. The respondents were assured of confidentiality and provided with an explanation regarding the purpose of the study and the importance of their contribution. The subjects gave verbal consent to participate in the study.
Table 1. Sociodemographic characteristics of the respondents $(\mathrm{n}=100)$

\begin{tabular}{|c|c|c|}
\hline Characteristic & Parameter & Percentage \\
\hline \multirow[t]{2}{*}{ Gender } & male & 60 \\
\hline & female & 40 \\
\hline \multirow[t]{3}{*}{ Age, years } & $15-39$ & 13 \\
\hline & $40-64$ & 72 \\
\hline & $65-89$ & 15 \\
\hline \multirow[t]{2}{*}{ Nationality } & Kuwaiti & 37 \\
\hline & non-Kuwaiti & 63 \\
\hline \multirow[t]{7}{*}{ Educational level } & never went to school & 16 \\
\hline & primary school & 13 \\
\hline & intermediate school & 24 \\
\hline & secondary school & 19 \\
\hline & diploma & 5 \\
\hline & university & 22 \\
\hline & postgraduate studies & 1 \\
\hline \multirow[t]{8}{*}{ Employment } & unemployed & 1 \\
\hline & labour & 20 \\
\hline & professional & 13 \\
\hline & businessmen & 4 \\
\hline & clerical & 23 \\
\hline & student & 2 \\
\hline & housewife & 27 \\
\hline & retired & 10 \\
\hline \multirow[t]{4}{*}{ Residence } & capital & 15 \\
\hline & Hawalli & 65 \\
\hline & Farwanhiya & 17 \\
\hline & others & 3 \\
\hline \multirow[t]{3}{*}{ Monthly income } & less than $500 \mathrm{KD}$ & 58 \\
\hline & $500-1,000 \mathrm{KD}$ & 35 \\
\hline & more than $1,000 \mathrm{KD}$ & 7 \\
\hline Membership in Kuwait & yes & 8 \\
\hline Diabetes Association & no & 92 \\
\hline
\end{tabular}

Data were entered in SPSS for Windows version 13 and analysed using simple frequencies and cross tabulation with $\chi^{2}$ test. $\chi^{2}$ test was used to evaluate the associations between the independent variables and the responses to the questions about health-seeking behaviour, self-medication with herbs and proprietary medicines. Statistical significance was defined a priori as $\mathrm{p}$ value $<0.05$.

\section{Results}

Of the 104 diabetic patients, 100 (96.2\%) agreed to participate in the survey. The respondents' mean age was $50.9 \pm 11.6$ years. Demographic data are shown in ta- 
Table 2. Responses to questions about health-seeking behaviour, differences by demographic variables $(\mathrm{n}=100)$

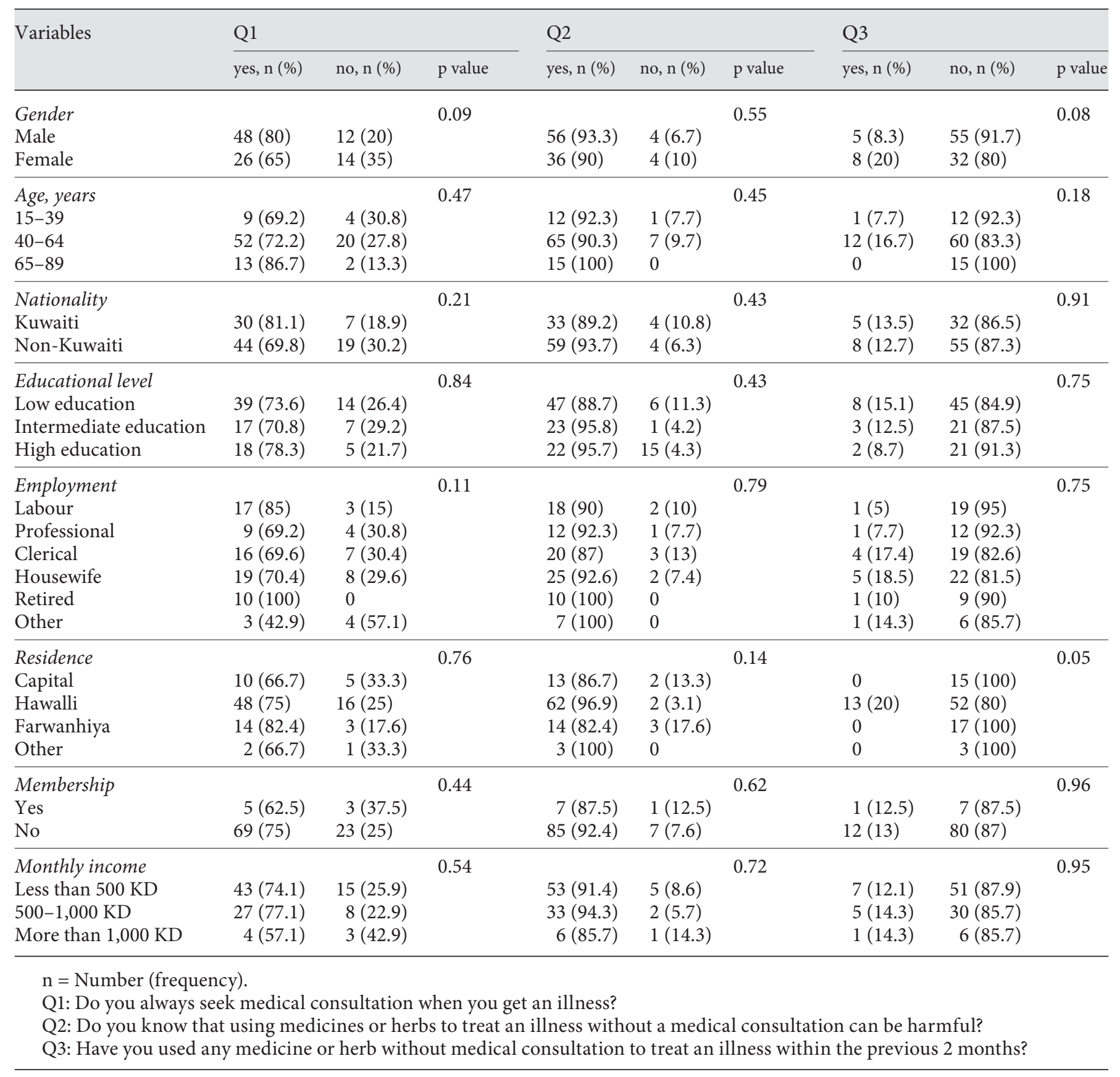

ble 1. Most $(n=63)$ of the respondents were non-Kuwaiti (expatriates) with low to intermediate level of education and had a monthly income of less than 1,000 KD. The majority (92\%) were not members of the Kuwait Diabetes Association, the mission of which is to increase the public awareness about diabetes and improve its health care.
Seventy-four (74\%) of the study participants reported that they seek medical consultation when they get an illness, $92 \%$ indicated that the use of medicines or herbs to treat an illness without a medical consultation can be harmful. Only 13 (13\%) of the study participants reported that they had used medicine or herbs without medical consultation to treat an illness within the previous 2 
Table 3. Responses to the question about self-medication with herbs, differences by sociodemographic variables $(\mathrm{n}=100)$

\begin{tabular}{|c|c|c|c|}
\hline \multirow[t]{2}{*}{ Variables } & \multicolumn{3}{|l|}{ Q4 } \\
\hline & yes, n (\%) & no, n (\%) & $\mathrm{p}$ value \\
\hline Gender & & & 0.77 \\
\hline Male & $5(8.3)$ & $55(91.7)$ & \\
\hline Female & $4(10)$ & $36(90)$ & \\
\hline Age, years & & & 0.92 \\
\hline $15-39$ & $1(7.7)$ & $12(92.3)$ & \\
\hline $40-64$ & $7(9.7)$ & $65(90.3)$ & \\
\hline $65-89$ & $1(6.7)$ & $14(93.3)$ & \\
\hline Nationality & & & 0.81 \\
\hline Kuwaiti & $3(8.1)$ & $34(91.9)$ & \\
\hline Non-Kuwaiti & $6(9.5)$ & $57(90.5)$ & \\
\hline Educational level & & & 0.46 \\
\hline Low education & $3(5.7)$ & $50(94.3)$ & \\
\hline Intermediate education & $3(12.5)$ & $21(87.5)$ & \\
\hline High education & $3(13)$ & $20(87)$ & \\
\hline Employment & & & 0.84 \\
\hline Labour & $1(5)$ & $19(95)$ & \\
\hline Professional & $2(15.4)$ & $11(84.6)$ & \\
\hline Clerical & $1(4.3)$ & $22(95.7)$ & \\
\hline Housewife & $3(11.1)$ & $24(88.9)$ & \\
\hline Retired & $1(10)$ & $9(90)$ & \\
\hline Others & $1(14.3)$ & $6(85.7)$ & \\
\hline Residence & & & 0.14 \\
\hline Capital & 0 & $15(100)$ & \\
\hline Hawalli & $9(14.1)$ & $55(85.9)$ & \\
\hline Farwanhiya & 0 & $17(100)$ & \\
\hline Other & 0 & $3(100)$ & \\
\hline Membership & & & 0.35 \\
\hline Yes & 0 & $8(100)$ & \\
\hline No & $9(9.8)$ & $83(90.2)$ & \\
\hline Monthly income & & & 0.66 \\
\hline Less than $500 \mathrm{KD}$ & $4(6.9)$ & $54(93.1)$ & \\
\hline $500-1,000 \mathrm{KD}$ & $4(11.4)$ & $31(88.6)$ & \\
\hline More than $1,000 \mathrm{KD}$ & $1(14.3)$ & $6(85.7)$ & \\
\hline
\end{tabular}

$\mathrm{n}=$ Number (frequency).

Q4: Have you used any herb to treat your diabetes?

months of the study period. Reasons given for not seeking medical consultation included previous experience with similar ailments (33.3\%), and others, such as previous experience of friends who had a similar ailment or had known about the disease and its treatment from information acquired through the mass media (66.7\%).

Responses to questions concerning health-seeking behaviour and self-medication with herbs according to differences in sociodemographic variables are shown in tables 2 and 3, respectively. No statistically significant relationships were identified for any question and sociodemographic variables.

Only 9 of the respondents reported that they used herbs to treat diabetes. Sources of information about the use of the herbs included relatives or friends: $44.5 \%$; previous experience of use: $22.2 \%$, and mass media: $33.3 \%$. Of the 9 that used herbs, 5 (55.6\%) obtained the herb from local herbal shops, 2 (22.2\%) from relatives or friends, and the remaining 2 from the supermarket. Only 3 reported that their physicians knew that they were using herbs to treat diabetes. Of the 9 , only 2 indicated that they knew that the use of herbs can interact with their medications and may be harmful.

Of the study population of 100 , only 2 reported that they had used proprietary medicines without a medical consultation within 2 months prior to the study period: 1 used an analgesic, the other used diet pills, vitamins, and an analgesic. The main source for obtaining the medicines was the pharmacy. However, one obtained information related to the use of medicine from a relative or friend and another from the mass media. Both were females within the range of 15-39 years, having a monthly income of less than 1,000 KD. Neither was a member of the Kuwait Diabetes Association. There was no significant association between self-medication with medicines and the sociodemographic characteristics of the study participants $(\mathrm{p}>0.05)$.

\section{Discussion}

The prevalence of use of herbs and/or proprietary medicines without medical consultation of this study was low (13\%) compared to that of previous studies [6-13] probably due to several factors. In Kuwait, government health facilities provide free health care to Kuwaiti citizens and a flat user fee for expatriates under a compulsory health insurance scheme. Some of the prescriptiononly drugs such as antibiotics, which are commonly obtained from private pharmacies without a prescription in developing countries, are dispensed in Kuwait with a prescription. Furthermore, the majority of the population in Kuwait trusts physicians more than pharmacists because a pharmacist is seen as a drug dispenser with a financial conflict of interest. Another probable explanation is that all respondents were interviewed during their visits to the health facilities to seek medical consultation and as such were more interested in their health status. Thus the 
study population may not reflect a well-represented sample of diabetic patients in Kuwait.

The percentage of respondents taking a herbal remedy to treat diabetes in this study was low (9\%) compared to that of other previous studies of self-medication with herbs [7]. It has been reported that self-medication with herbs is highly associated with middle age, female gender, and low income [7], but in this study no association was seen between self-medication and middle age and lowwage earners. The majority of the study participants claimed that they did not use any herb without medical consultation. These were positive findings because the use of herbs as the sole means of treatment gives rise for concern in view of the morbidity potential arising from inadequate disease control. Moreover, the use of herbs as an adjunct to prescribed medicines may increase the risk from interactions with prescribed medication, which is difficult to assess because the effects of many herbs are incompletely documented.

Equally, self-medication with proprietary medicines was very low (2\%) in this study compared to previous studies. Reasons reported for self-medication behaviour included the perception that pharmacies were low-cost alternatives compared to other health care facilities, which charged consultation and laboratory fees. In addition, no waiting time was involved with private pharmacies. Some respondents relied on the fact that they had previous positive experience with similar ailments, giving them the confidence to self-medicate [5]. In our study it was found that the main reason was previous experience of the patient or his/her friend with similar ailments.

Nevertheless, appropriate self-medication with OTC drugs may reduce the number of physician visits, the waiting time at the clinics and allow fewer consultations on minor illness, which will free up more consultation time for more serious conditions $[7,8]$. Although this may provide more impact in improving the quality of care, it requires public education about minor illness, OTC drugs and herbs, restricted dispensing of prescription-only drugs, and implementation of pharmaceutical care practice in the community pharmacies. Indeed community pharmacists can play an active role in the provision of primary health care by attending to minor ailments and referring patients to physicians when patients require further investigation [16].

\section{Limitations of the Study}

A face-to-face structured interview was used in this study to achieve a high response rate. This method has a disadvantage in that the response might be different from self-administered surveys due to the non-response bias, which is the social desirability and the possibility that study participants may have offered favourable answers (responded in a socially accepted way). In this respect, this study had no means of verifying the study participants' responses, which were taken at face value. In addition, the small sample size may not have allowed for the identification of significant differences in the comparisons made. This study could be utilized as a pilot study for the design of a wider study including a larger sample size and a better representation of the diabetic population in Kuwait by interviewing diabetics in other settings such as pharmacies and households to provide more valid results.

\section{Conclusions}

The prevalence of self-medication with medicines, including herbs, among diabetic patients in Kuwait is low. There was no significant association between self-medication with medicines including herbs and the sociodemographic characteristics of the respondents, and this may be attributed to the small sample size, which may not be representative of the total population of diabetic patients in Kuwait. The enforcement of a strict prescription policy and coverage of medical consultation by health insurance might have contributed to the low self-medication practices among diabetic patients.

\section{Acknowledgements}

We gratefully acknowledge Prof. Mohammed Mosa, Director of Research Unit, Kuwait Institute for Medical Specialization, Ministry of Health, who granted permission to conduct this study at the health care facilities of Kuwait, and Dr. Ahmed Elhashim for revising the manuscript.

\section{References}

Med Princ Pract 2008;17:315-320
1 World Health Organization: Guidelines for the regulatory assessment of medicinal products for use in self-medication. WHO 2000;WHO/EDM/QSM/00.1.

2 Sclafer J, Slamet L, Visscher G: Appropriateness of self-medication: method development and testing in urban Indonesia. J Clin Pharm Ther 1997;22:261-272.

-3 Nokes K, Prince RJ, Achieng R, AagaardHansen J, Ouma J: Children and medicines: self-treatment of common illnesses among Luo schoolchildren in western Kenya. Soc Sci Med 2000;50:1771-1783. 
4 Hamel MJ, Odhacha A, Roberts JM, Deming MS: Malaria control in Bungoma District, Kenya: a survey of home treatment of children with fever, bed net use and attendance at antenatal clinics. Bull World Health Organ 2001;79:1014-1023.

5 World Health Organization: Promoting rational use of medicines: core components. WHO Policy Perspectives on Medicines. WHO 2002;WHO/EDM/2002.3.

-6 Abahussain E, Matowe LK, Nichollos PJ: Self-reported medication use among adolescents in Kuwait. Med Princ Pract 2005;14: 162-164.

7 Awad AI, Eltayeb IB, Capps PA: Self-medication practices in Khartoum state, Sudan. Eur J Clin Pharmacol 2006;62:317-324.

$>8$ Awad AI, Eltayeb IB, Matowe LK, Thalib L: Self-medication with antibiotics and antimalarials in the community of Khartoum state, Sudan. J Pharm Pharm Sci 2005;8: 326-331.
-9 Drug Utilization Research Group, Latin America: Multicenter study on self-medication and self-prescription in six Latin American countries. Clin Pharm Ther 1997;61: 488-493.

10 Calva J, Bojalil R: Antibiotic use in a periurban community in Mexico: a household and drug store survey. Soc Sci Med 1996;42:11211128 .

11 Shankar PR, Partha P, Shenoy N: Self-medication and non-doctor prescription practices in Pokhara valley, Western Nepal: a questionnaire-based study. BMC Fam Pract 2002; 3:17.

12 Grigoryan L, Haaijer-Ruskamp F, Burgerhof J, Mechtler R, Deschepper R, Tambic-Andrasevic A, Andrajati R, Monnet DL, Cunney R, Di Matteo A, Edelstein H, Valinteliene R, Alkerwi A, Scicluna EA, Grzesiowski P, Bara AC, Tesar T, Cizman M, Campos J, Lundborg CS, Birkin J: Self-medication with antimicrobial drugs in Europe. Emerg Infect Dis 2006;12:452-459.
3 Svensson E, Haaijer-Ruskamp FM, Lundborg CS: Self-medication with antibiotics in a Swedish general population. Scand J Infect Dis 2005;37:399-400.

14 Effects of Over-the-Counter (OTC) Drugs on Diabetes and Its Complications. Available at URL: http://www2.eckerd.com/content. asp? content $=$ healthcare/oncall/diabetes otc/default

15 Kudulo GB: The effect of 3-month ingestion of Ginkgo biloba extract on pancreatic betacell function in response to glucose loading in normal glucose tolerant individuals. J Clin Pharmacol 2000;40:647-654.

16 World Health Organization: The role of pharmacist in self-care and self-medication. Report of the 4th WHO Consultative Group on the role of the Pharmacist. WHO 1998;WHO/DAP/98.13. 